\title{
ORIGINAL
}

\section{High risk of thrombosis in patients with severe SARS-CoV-2 infection: a multicenter prospective cohort study}

Julie Helms ${ }^{1,2}$, Charles Tacquard ${ }^{3}$, François Severac ${ }^{4}$, lan Leonard-Lorant ${ }^{5}$, Mickaël Ohana ${ }^{5}$, Xavier Delabranche ${ }^{3}$, Hamid Merdji 1,6, Raphaël Clere-Jehl 1,2, Malika Schenck ${ }^{7}$, Florence Fagot Gandet ${ }^{7}$, Samira Fafi-Kremer ${ }^{2,8}$, Vincent Castelain ${ }^{7}$, Francis Schneider ${ }^{7}$, Lélia Grunebaum ${ }^{9}$, Eduardo Anglés-Cano ${ }^{10}$, Laurent Sattler ${ }^{9}$, Paul-Michel Mertes ${ }^{3}$, Ferhat Meziani ${ }^{1,6^{*}}$ and CRICS TRIGGERSEP Group (Clinical Research in Intensive Care and Sepsis Trial Group for Global Evaluation and Research in Sepsis)

(c) 2020 Springer-Verlag GmbH Germany, part of Springer Nature

\begin{abstract}
Purpose: Little evidence of increased thrombotic risk is available in COVID-19 patients. Our purpose was to assess thrombotic risk in severe forms of SARS-CoV-2 infection.

Methods: All patients referred to 4 intensive care units (ICUs) from two centers of a French tertiary hospital for acute respiratory distress syndrome (ARDS) due to COVID-19 between March 3rd and 31st 2020 were included. Medical history, symptoms, biological data and imaging were prospectively collected. Propensity score matching was performed to analyze the occurrence of thromboembolic events between non-COVID-19 ARDS and COVID-19 ARDS patients.

Results: 150 COVID-19 patients were included (122 men, median age 63 [53; 71] years, SAPSII 49 [37; 64] points). Sixty-four clinically relevant thrombotic complications were diagnosed in 150 patients, mainly pulmonary embolisms (16.7\%). 28/29 patients (96.6\%) receiving continuous renal replacement therapy experienced circuit clotting. Three thrombotic occlusions (in 2 patients) of centrifugal pump occurred in 12 patients (8\%) supported by ECMO. Most patients (>95\%) had elevated D-dimer and fibrinogen. No patient developed disseminated intravascular coagulation. Von Willebrand (VWF) activity, VWF antigen and FVIII were considerably increased, and 50/57 tested patients (87.7\%) had positive lupus anticoagulant. Comparison with non-COVID-19 ARDS patients ( $n=145)$ confirmed that COVID-19 ARDS patients $(n=77)$ developed significantly more thrombotic complications, mainly pulmonary embolisms (11.7 vs. $2.1 \%, p<0.008)$. Coagulation parameters significantly differed between the two groups.
\end{abstract}

Conclusion: Despite anticoagulation, a high number of patients with ARDS secondary to COVID-19 developed life-threatening thrombotic complications. Higher anticoagulation targets than in usual critically ill patients should therefore probably be suggested.

Keywords: COVID-19, ARDS, Thrombosis, Lupus anticoagulant, Coagulopathy

\footnotetext{
*Correspondence: Ferhat.Meziani@chru-strasbourg.fr

1 Service de Médecine Intensive Réanimation, Nouvel Hôpital

Civil, Hôpitaux universitaires de Strasbourg, 1, Place de l'Hôpital, 67091 Strasbourg Cedex, France

Full author information is available at the end of the article
}

\section{实 Springer}




\section{Introduction}

Patients with severe acute respiratory syndrome (ARDS) due to SARS-CoV-2 infection, also known as coronavirus disease 2019 (COVID-19), who are admitted to intensive care units (ICUs) mainly develop respiratory and digestive symptoms [1, 2]. However, some patients may also develop coagulopathy, then associated with poor prognosis [3]. In a retrospective series of 183 consecutive patients, Tang et al. reported that $71.4 \%$ of non-survivors met the criteria of disseminated intravascular coagulation (DIC), while only $0.6 \%$ of survivors did. In 99 Chinese patients, Chen et al. [4] also reported abnormal "coagulation function", including increased D-dimers in 36 patients (36\%), decreased prothrombin time (PT) in 30 patients (30\%), or increased activated partial thromboplastin time (aPTT) in 16 patients (16\%). Similarly, among 13 patients admitted to ICU, Wang et al. [5] reported that prothrombin time and D-dimer level on admission were significantly higher in ICU patients than in nonICU patients. As is the case with sepsis, prophylactic anticoagulation of patients with severe COVID-19 may be recommended [6]. Recent recommendations on coagulopathy management, based on the follow-up of standard coagulation markers (D-dimers, prothrombin time, fibrinogen, and platelet count), have been put forward by the International Society of Thrombosis and Haemostasis (ISTH) [7]. In another retrospective study stratifying patients based on sepsis-induced coagulopathy (SIC) score or D-dimer level, Tang et al. [8] suggested that heparin would decrease mortality in severe COVID-19 patients who met the SIC criteria or have markedly elevated D-dimers.

Despite increasing evidence of coagulation disorders, based on these retrospective data in a small number of patients, no data are available for the most severe patients, i.e., those admitted to ICU. In addition, none of the published articles describe the clinical or radiological issues related to these coagulation disorders [3-5]. The clinical relevance of these results may still be questionable.

On the basis of a comprehensive clinical examination, backed with biological and radiological data of a homogeneous prospective cohort of critically ill patients with ARDS due to SARS-CoV-2 infection, admitted to 4 intensive care units (ICUs) in two centers of a French tertiary hospital, we have aimed at describing the COVID-19-induced thrombotic complications and comparing them with non-COVID-19 ARDS patients.

\section{Take-home message}

In a prospective cohort study, we have shown that sixty-four clinically relevant thrombotic complications were diagnosed in 150 patients with COVID-19 ARDS during their ICU stay, mainly pulmonary embolisms (25 patients, 16.7\%). Despite anticoagulation, a high number of patients with COVID-19 ARDS developed life-threatening thrombotic complications, meaning that higher anticoagulation targets than in usual critically ill patients should probably be considered.

\section{Patients and methods \\ Patients}

Between March 3rd and March 31st 2020, all patients referred for ARDS [9] due to SARS-CoV-2 were prospectively included on admission in four intensive care units (ICUs) in two centers of a French tertiary hospital. There was no exclusion criterion. Patients were managed following current guidelines [6] without specific therapeutic intervention. Approval was obtained from the local ethics committee of the University Hospital of Strasbourg (reference CE-2020-34). This study encompasses all demographic characteristics, medical history, clinical signs, biological and imaging data. Data were analyzed on April the 7th, which means at least 7 days of follow-up for the most recent patients.

A historical prospective cohort of "non-COVID-19 ARDS" patients (NCT \#02391792) included between 2014 and 2019 was used for the comparison of COVID19 ARDS to non- COVID-19 ARDS. All the patients had a bacterial or viral ARDS defined according to Berlin definition [9]. Their characteristics are summarized in Table 1.

\section{Outcomes}

The primary end-point was to compare the occurrence of any thrombotic event (deep vein thrombosis, pulmonary embolism, myocardial infarction, mesenteric ischemia, lower limb ischemia, cerebral ischemic attack) between patients with COVID-19 ARDS and patients with nonCOVID-19 ARDS. The secondary endpoints were to compare: the occurrence of each of the aforementioned thrombotic complications, the occurrence of RRT filter coagulation, the median lifespan of each RRT circuit, the occurrence of ECMO oxygenator coagulation, the occurrence of hemorrhagic complications and the results of coagulation tests.

\section{Laboratory analysis}

Platelet count and coagulation tests were performed daily during the ICU stay, including PT, antithrombin activity (AT), fibrinogen, D-dimers and aPTT in order to perform 
Table 1 Characteristics of COVID-19 ARDS and non-COVID-19 ARDS

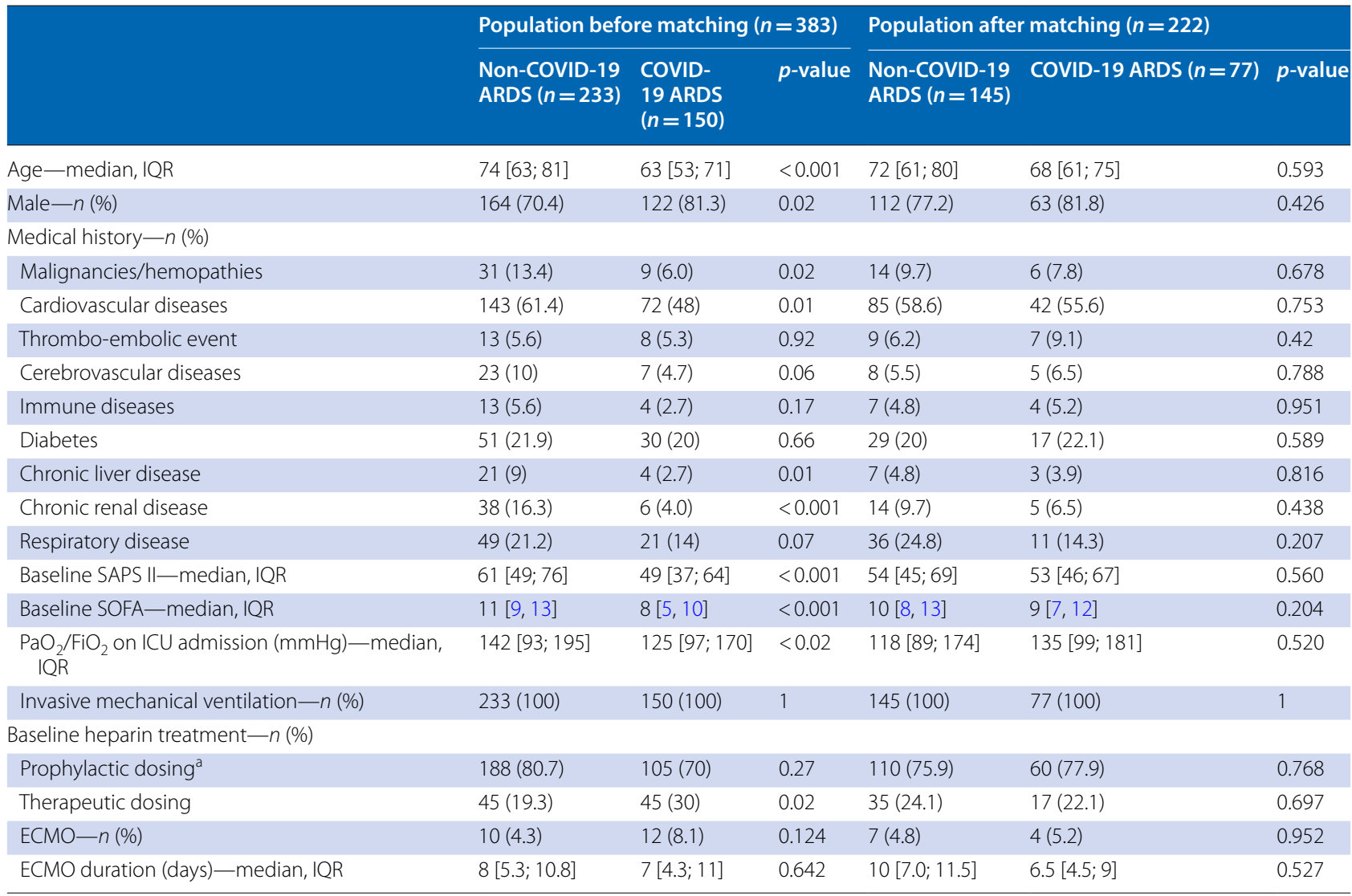

SOFA, sequential organ failure assessment; SAPSII, simplified acute physiology score II

a Prophylactic dosing was $4000 \mathrm{UI} /$ day for low molecular weight heparin or if contra-indicated, unfractioned heparin at 5-8 U/kg/h

DIC scores. Factor V (FV), von Willebrand factor (vWF) antigen, vWF activity, and factor VIII (FVIII) activity were performed. Lupus anticoagulant was searched when a coagulation disorder was suspected, based on a prolonged aPTT at ICU admission or on the occurrence of a thrombotic event during ICU stay. Please refer to supplementary material for further details.

\section{DIC scoring systems}

The JAAM-DIC 2016 score [10], ISTH overt-DIC score [11] and SIC score [8] were calculated daily until day 7. Scores were considered positive as commonly accepted, if ISTH overt-DIC was 5 points or more, JAAM-DIC score was 4 points or more and if SIC was 4 points or more.

\section{Imaging}

Patients with suspected pulmonary embolism, based on their clinical (worse $\mathrm{PaO}_{2} / \mathrm{FiO}_{2}$ despite inhaled nitric oxide or after prone positioning or hemodynamic impairment requiring fluid challenge and/or increased norepinephrine infusion rate, dilated right ventricle-even without acute cor pulmonale) or laboratory parameters evolution (a rapid elevation of D-dimer despite anticoagulation), had a CT pulmonary angiography (CTPA) done, either at the admission in ICU or during their stay. All CTPA were acquired on $64+$ row scanners, after injection of $50-75 \mathrm{~mL}$ of high concentration iodine contrast media, with the use of a bolus-tracking technique and a threshold of $160 \mathrm{HU}$ to $250 \mathrm{HU}$ in the main pulmonary artery. When established, pulmonary embolism was classified as troncular, lobar, segmental or sub-segmental, based on the location of the most proximal luminal defect.

Patients with suspected peripheral arterial ischemia were explored with CT angiography (CTA). Lower-limb CTA were acquired on $64+$ row machines, with arterial phase after injecting $100 \mathrm{~mL}$ of high concentration iodine contrast media.

Patients with suspected mesenteric ischemia, based on clinical presentation and/or biological abnormalities, had a contrast-enhanced chest abdomen and pelvis CT (CAP CT). All CAP CT were acquired on $64+$ row machines, with mandatory unenhanced, arterial and 
venous abdomino-pelvic phases, after injecting $100 \mathrm{~mL}$ of high concentration iodine contrast media.

Patients with suspicion of stroke, based on pathological neurological examination, had either a non-contrast brain CT and/or a brain MRI with diffusion weighted imaging and 3D FLAIR acquisitions.

All CT and MR examinations were read by consultant radiologists specialized in emergency radiology.

\section{Statistic}

Continuous variables are presented as median with the first and third quartile and were compared using nonparametric Wilcoxon tests. Categorical variables are presented as numbers and proportions and were compared using Pearson's $\chi^{2}$ tests or Fisher's exact tests. In order to compare the outcomes in this observational study, a propensity score analysis was performed. Propensity scores was generated using a multivariable logistic regression model with the group (non-COVID-19 ARDS or COVID-19 ARDS) as the dependent variable and baseline characteristics that were unbalanced between groups or had clinical relevance as the independent variables (age, sex, medical history of malignancies, cardiovascular diseases, cerebrovascular diseases, venous thrombo-embolic event, immune diseases, chronic liver diseases, chronic renal diseases, respiratory diseases, SAPS II, SOFA, $\mathrm{PaO}_{2} / \mathrm{FiO}_{2}$ on ICU admission, anticoagulant treatment and ECMO). The COVID-19 and non-COVID-19 patients were then paired 1:3 on these propensity scores with a caliper size of $0.1 \times \operatorname{logit}$ [SD of the propensity score]. In order to take into account the matching, variables were then compared using GEE (generalized estimating equation) models with an unstructured covariance matrix. Binomial distribution was used for binary variables, and Gamma distribution was used for continuous variable. Goodness of fit for Gamma distribution was assessed using histograms and quantiles plots. Sensitivity analysis was performed using multivariable logistic regression models on the whole population. Results are presented as odds ratio with $95 \%$ confidence intervals. A $p$ value $<0.05$ was considered as statistically significant. All the analyses were performed using R software version 3.6.0. (R Core Team (2019). R: A language and environment for statistical computing. R Foundation for Statistical Computing, Vienna, Austria. URL https:// www.R-project.org/).

\section{Results}

\section{Baseline characteristics of the patients}

One hundred and fifty consecutive patients, with positive real-time reverse transcriptase PCR tests for COVID19 , admitted to 4 participating ICUs were included in the study. Median age was $63[53 ; 71]$ years, and the male-to-female ratio was $122 / 28$ ( $81.3 \%$ of men). The median of simplified acute physiology score (SAPS) II was 49 [37; 64] points. The median length of stay in ICU was $9.6 \pm 4.2$ days and mortality rate was $8.7 \%$, considering that 101 patients $(67.3 \%)$ were still intubated at the time of data analysis. Thirty-six patients had been discharged from ICU by time of data analysis. Eighty-four patients $(60 \%)$ received lopinavir + ritonavir, $8(5.3 \%)$ remdesivir, 49 (32.7\%) hydroxychloroquine, and 9 (7.5\%) did not received any antiviral treatment. Medical history, patient characteristics, thrombotic/ischemic and hemorrhagic complications during ICU stay of both COVID-19 and non-COVID-19 patients are summarized in Table 1.

\section{Thrombotic and ischemic complications}

Sixty-four clinically relevant thrombotic complications were diagnosed in 150 patients during their ICU stay, mainly pulmonary embolisms (Fig. 1). One hundred CTPA were performed in 99 patients to investigate the cause of a respiratory re-aggravation or because of a significant increase of D-dimers. Twenty-five (25\%) showed pulmonary embolisms ( 24 men, mean age 62 years old): 9 troncular, 8 lobar, 5 segmental and 3 subsegmental pulmonary embolisms. Pulmonary embolism was diagnosed in median 5.5 [2.8; 9.3] days after ICU admission.

Fifteen brain CT and 10 brain MRI were performed in 25 patients because of pathological neurological examinations, and 4 showed hemorrhagic complications or ischemic strokes. Two CT were performed in a context of recent head trauma after a fall, but none showed sign of ischemic stroke. In one patient, there was a complete occlusion of the right internal carotid artery, possibly preexisting to COVID-19 infection, without any sign of ischemic stroke.

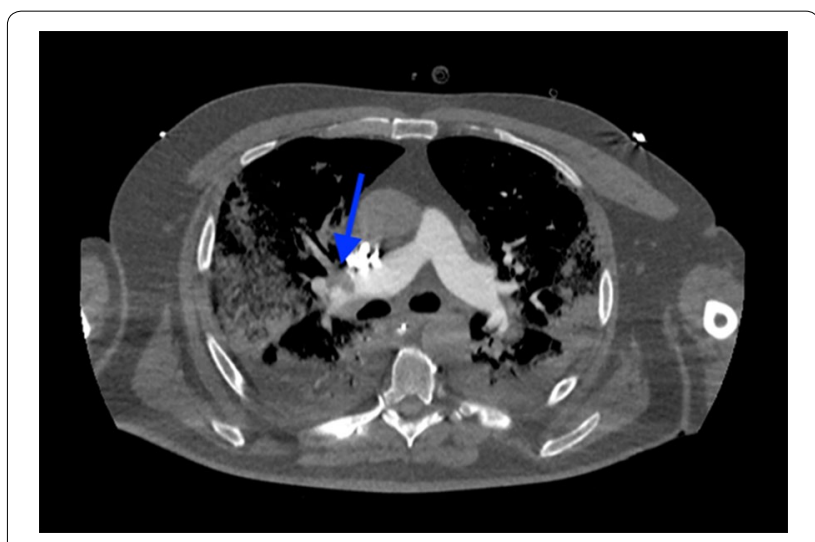

Fig. 1 66-year-old man at day 8 of ICU stay for ARDS secondary to Covid-19. CTPA demonstrating a proximal right pulmonary artery luminal defect and major bilateral alveolar consolidation 
Two patients had a left cerebellar ischemic stroke in MRI, which was acute in one case with hyperintensity on diffusion weighted imaging and decreased diffusion coefficient and probably preexisting to COVID-19 infection in the other case because of ADC increase, lack of contrast enhancement and absence of mass effect; the third patient has bilateral multiple periventricular ischemic lesions. The last one had an acute voluminous frontotemporal intra-parenchymatous hematoma and multiple recent ischemic lesions.

Twenty-eight patients out of 29 (96.6\%) receiving continuous renal replacement therapy (RRT) experienced circuit clotting. The median lifespan of an RRT circuit was $1.5[1 ; 2]$ days, compared to the 3 days recommended by the manufacturer, and the total number of circuits was used 141 circuits for 230 days of continuous RRT (4.9 devices/patient).

Twelve patients (8\%) were supported by extracorporeal membrane oxygenation (ECMO): 11 with veno-venous ECMO because of respiratory failure, and 1 patient with veno-arterial ECMO because of respiratory failure complicated with cardiogenic shock due to pulmonary embolism.

We identified 3 thrombotic occlusions of centrifugal pump in 2 patients, needing its prompt replacement after a runtime of 5 days in the first patient and 4 and 7 days in the second one.

No patients suffered from a myocardial infarction during the ICU stay, although a high number of the patients (48\%) suffered from cardiovascular comorbidities. A 62-year-old patient, without any cardiovascular medical history except smoking cessation for over 20 years and dyslipidemia, developed an acute limb ischemia. His medical history showed no obliterating arteriopathy of the lower limbs, he did not receive catecholamines, and no atrial fibrillation was reported during his stay. A segmental pulmonary embolism was also diagnosed on a CTPA performed the same day because of persistent hypoxemia.

Mesenteric ischemia was suspected in 5 patients, with positive CAP CT in one case $(30 \mathrm{~cm}$ of non-enhancing bowel).

No patient suffered from digital/toes necrosis or purpura.

The antiviral therapy item was not associated with thrombogenic tendencies (data not shown).

\section{Hemorrhagic complications}

Only 4 patients $(2.7 \%)$ presented hemorrhagic complications. Patients 1 and 2 had recent head trauma before ICU admission; the first one was diagnosed with an intraaxial hematoma; the second one with a diffuse intra and extra-axial hemorrhagic lesions. The third patient had an intra-parenchymatous hematoma (described above). The fourth patient developed hemorrhagic complications due to ECMO, with a voluminous hematoma at the insertion site of the cannula (scarpa) requiring the hematoma removal and local coagulation.

\section{Coagulation disorders}

At baseline, most patients (>95\%) had elevated D-dimer and fibrinogen levels. Platelets, prothrombin time, aPTT and antithrombin remained within normal ranges in 120 (80\%), 108 (72\%), and 100 patients (66.7\%), respectively, which explains the normal JAAM-DIC (<4 points) in 144 patients $(96 \%)$ and normal ISTH $(<5$ points $)$ scores in all patients. Median scores were $0[0 ; 1]$ and $2[2,3]$ points for JAAM-DIC and ISTH scores, respectively. Only 6 patients $(2.7 \%)$ had a positive JAAM-DIC score, and none had a positive ISTH score. Even the SIC score, which detects patients "at risk of developing DIC", was positive in only 22 patients $(14.7 \%)$.

Von Willebrand factor (vWF) activity and vWF antigen (vWF:Ag) were considerably increased, as well as factor VIII. Furthermore, 50 patients out of the 57 tested $(87.7 \%)$ had positive lupus circulating anticoagulant during their ICU stay (Table 2).

\section{Table 2 Coagulation parameters of COVID-19 patients}

All patients $(n=150)$

\begin{tabular}{|c|c|}
\hline $\begin{array}{l}\text { Platelet count }\left(10^{9} / \mathrm{L}\right) \text { - normal range: } \\
150-400.10^{9} / \mathrm{L}\end{array}$ & $200[152 ; 267]$ \\
\hline aPTT—normal range: $0.7-1.2$ & $1.2[1.1 ; 1.3]$ \\
\hline PT (\%)—normal range: $>70 \%$ & $84[73 ; 91]$ \\
\hline INR_-normal range: 1.00-1.15 & $1.12[1.05 ; 1.25]$ \\
\hline D-dimers (mg/L) —normal range: $<0.5 \mathrm{mg} / \mathrm{L}$ & $2.27[1.16 ; 20]$ \\
\hline Fibrinogen (g/L)—normal range: $2-4 \mathrm{~g} / \mathrm{L}$ & $6.99[6.08 ; 7.73]$ \\
\hline $\begin{array}{l}\text { Antithrombin activity (\%) - normal range: } \\
50-150 \%\end{array}$ & $91[78 ; 102]$ \\
\hline Factor V (\%)—normal range: > 70\% & $136[115 ; 150]$ \\
\hline Factor VIII (\%)—normal range: 60-150\% & $341[258 ; 416]$ \\
\hline vWF activity (\%) & $328[212 ; 342]$ \\
\hline vWF antigen (\%) —normal range: $50-150 \%$ & $455[350 ; 521]$ \\
\hline Lupus anticoagulant ${ }^{\mathrm{a}}-n(\%)$ & $50 / 57(87.7)$ \\
\hline Screen patient (s) & $68.6[59.5 ; 85.4]$ \\
\hline Screen ratio—normal range: $<1.2$ & $1.63[1.43 ; 2.04]$ \\
\hline Confirm patient (s) & $43.9[40.9 ; 48.4]$ \\
\hline Confirm ratio—normal range: $<1.2$ & $1.25[1.13 ; 1.46]$ \\
\hline Screen/confirm ratio—normal range: $<1.2$ & $1.4[1.25 ; 1.48]$ \\
\hline
\end{tabular}

All results are given in median [IQR], except if specified otherwise

aPTT, activated partial thromboplastin time; INR, international normalized ratio; PT, prothrombin time; vWF, von Willebrand factor

${ }^{\text {a }}$ Measured during ICU stay 
There was no heparin-induced thrombocytopenia in the 4 patients in whom it was searched because the clinical or biological data might have been compatible with this diagnosis.

\section{Comparing COVID-19 ARDS with non-COVID-19 ARDS patients}

Seventy-seven patients with COVID-19 ARDS or 145 patients with non-COVID-19 ARDS were matched. Thirty-five COVID-19 patients were matched with 1 non-COVID-19 patient, 16 COVID-19 patients with 2 non-COVID-19 patients, and 26 COVID-19 patients with 3 non-COVID-19 patients. Characteristics of both COVID-19 and non-COVID-19 patients are summarized in Table 1 and their outcomes in Table 3. The sex, age, medical history, organ failures and severity score (Sepsis-related Organ Failure Assessment-SOFA, SAPS II), $\mathrm{PaO}_{2} / \mathrm{FiO}_{2}$ ratio, anticoagulant treatment at baseline and ECMO support after matching were not different between groups (Table 1).

As assessed after matching, more thrombotic complications were diagnosed in COVID-19 ARDS patients than in patients with non-COVID-19 ARDS (9 patients (11.7\%) versus 7 patients (4.8\%), OR 2.6 [1.1-6.1], $p=0.035)$, with significantly more pulmonary embolisms (9 patients $(11.7 \%)$ versus 3 patients $(2.1 \%)$, OR $6.2[1.6-23.4], p=0.008)$.
The total number of RRT circuits per dialyzed patient was higher in COVID-19 patients and their median lifespan shorter (Table 3).

Coagulation parameters also differed between the two groups (Fig. 2): prothrombin time, antithrombin, fibrinogen and platelets were significantly higher in COVID-19 patients compared to non-COVID-19 ARDS patients; aPTT and D-dimers were significantly lower in COVID19 patients.

Sensitivity analyses were performed to compare the occurrence of thromboembolic complications and pulmonary embolism on the whole population using multivariable logistic regression models incorporating covariates used to construct the propensity score. The adjusted odds ratios were similar to those calculated with propensity score analysis for both events $(\mathrm{OR}=2.7[1.1-$ 6.6], $p=0.028$ for thromboembolic complications and $\mathrm{OR}=9.3[2.2-40], p=0.003$ for pulmonary embolism).

\section{Discussion}

In a prospective cohort, we have evidenced the high prevalence of clinically relevant thrombosis, essentially pulmonary embolisms (16.7\%), in COVID-19 patients admitted to ICU for hypoxemic acute respiratory failure. These thrombotic complications occurred despite prophylactic or therapeutic anticoagulation.

A systemic inflammatory response syndrome, assessed by high fibrinogen, was present in all patients and was responsible for activation of blood coagulation

Table 3 Outcomes of COVID-19 ARDS and non-COVID-19 ARDS

\begin{tabular}{|c|c|c|c|c|c|c|c|c|}
\hline & \multicolumn{4}{|c|}{ Population before matching $(n=383)$} & \multicolumn{4}{|c|}{ Population after matching $(n=222)$} \\
\hline & $\begin{array}{l}\text { Non-COVID- } \\
\text { 19-ARDS } \\
(n=233)\end{array}$ & $\begin{array}{l}\text { COVID- } \\
\text { 19-ARDS } \\
(n=150)\end{array}$ & OR $[95 \%$ IC $]$ & $p$-value & $\begin{array}{l}\text { Non-COVID- } \\
\text { 19-ARDS } \\
(n=145)\end{array}$ & $\begin{array}{l}\text { COVID- } \\
\text { 19-ARDS } \\
(n=77)\end{array}$ & OR [95\% IC] & $p$-value \\
\hline $\begin{array}{l}\text { Thrombo-embolic complica- } \\
\text { tions— } n(\%)\end{array}$ & $14(6)$ & $27(18)$ & $3.4[1.7-7.3]$ & $<0.001$ & $7(4.8)$ & $9(11.7)$ & $2.6[1.1-6.1]$ & 0.04 \\
\hline Pulmonary embolisms- $n(\%)$ & $3(1.3)$ & $25(16.7)$ & $15.2[4.5-80.4]$ & $<0.001$ & $3(2.1)$ & $9(11.7)$ & $6.2[1.6-23.4]$ & 0.01 \\
\hline Deep vein thrombosis—n (\%) & $3(1.3)$ & $3(2)$ & $1[0.1-9.2]$ & 1 & $2(1.4)$ & $0(0)$ & - & - \\
\hline Myocardial infarction $-n(\%)$ & $6(2.6)$ & $0(0)$ & $0[0-1.3]$ & 0.09 & $2(1.4)$ & $0(0)$ & - & - \\
\hline $\begin{array}{l}\text { Cerebral ischemic attack—n } \\
(\%)\end{array}$ & $1(0.4)$ & $2(1.3)$ & $3.1[0.2-185.5]$ & 0.68 & $0(0.0)$ & $0(0)$ & - & - \\
\hline Limb ischemia—n (\%) & $0(0)$ & $1(0.7)$ & $\operatorname{lnf}[0.0-\operatorname{lnf}]$ & 0.78 & $0(0.0)$ & $0(0)$ & - & - \\
\hline Mesenteric ischemia—n (\%) & $3(1.3)$ & $1(0.7)$ & $0.5[0.0-6.5]$ & 0.98 & $2(1.4)$ & $1(1.3)$ & 0.96 [0.09-9.8] & 0.97 \\
\hline $\begin{array}{l}\mathrm{Nb} \text { of RRT filter per dialyzed } \\
\text { patient-median, IQR }\end{array}$ & $1[2-1]$ & $3[2-7]$ & - & $<0.001$ & $2.0[1.0-2.5]$ & $3.0[2.0-6]$ & - & 0.03 \\
\hline $\begin{array}{l}\text { Nb of RRT filter per day of } \\
\text { RRT_-median, IQR }\end{array}$ & $0.3[0.3 ; 0.5]$ & $0.7[0.5 ; 1]$ & - & $<0.001$ & $0.3[0.3 ; 0.4]$ & $0.7[0.5 ; 1]$ & - & $<0.001$ \\
\hline $\begin{array}{l}\text { ECMO oxygenator thrombo- } \\
\text { sis- } n(\%)\end{array}$ & $1 / 10(10)$ & $2 / 12(16.7)$ & - & 0.59 & $1 / 7(14.3)$ & $0 / 4(0)$ & - & - \\
\hline $\begin{array}{l}\text { Hemorrhagic complications- } \\
n(\%)\end{array}$ & $1(1.8)$ & $4(2.7)$ & $2.4[0.27-28.5]$ & 0.6 & $2(1.4)$ & $0(0)$ & - & - \\
\hline
\end{tabular}

ARDS, acute respiratory distress syndrome; ECMO, extracorporeal membrane oxygenation; RRT, renal replacement therapy 


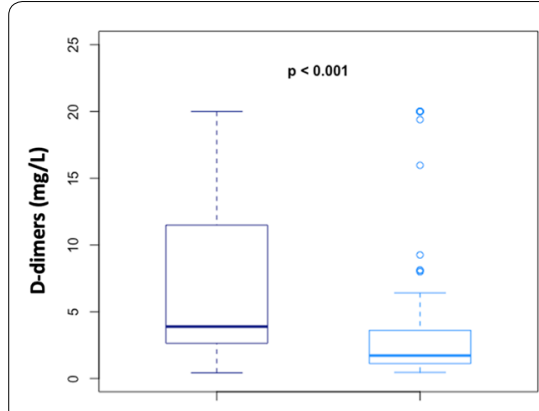

Non-Covid-19 ARDS Covid-19 ARDS

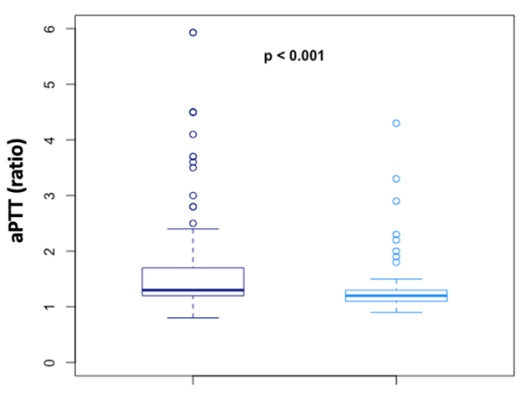

Non-Covid-19 ARDS Covid-19 ARDS
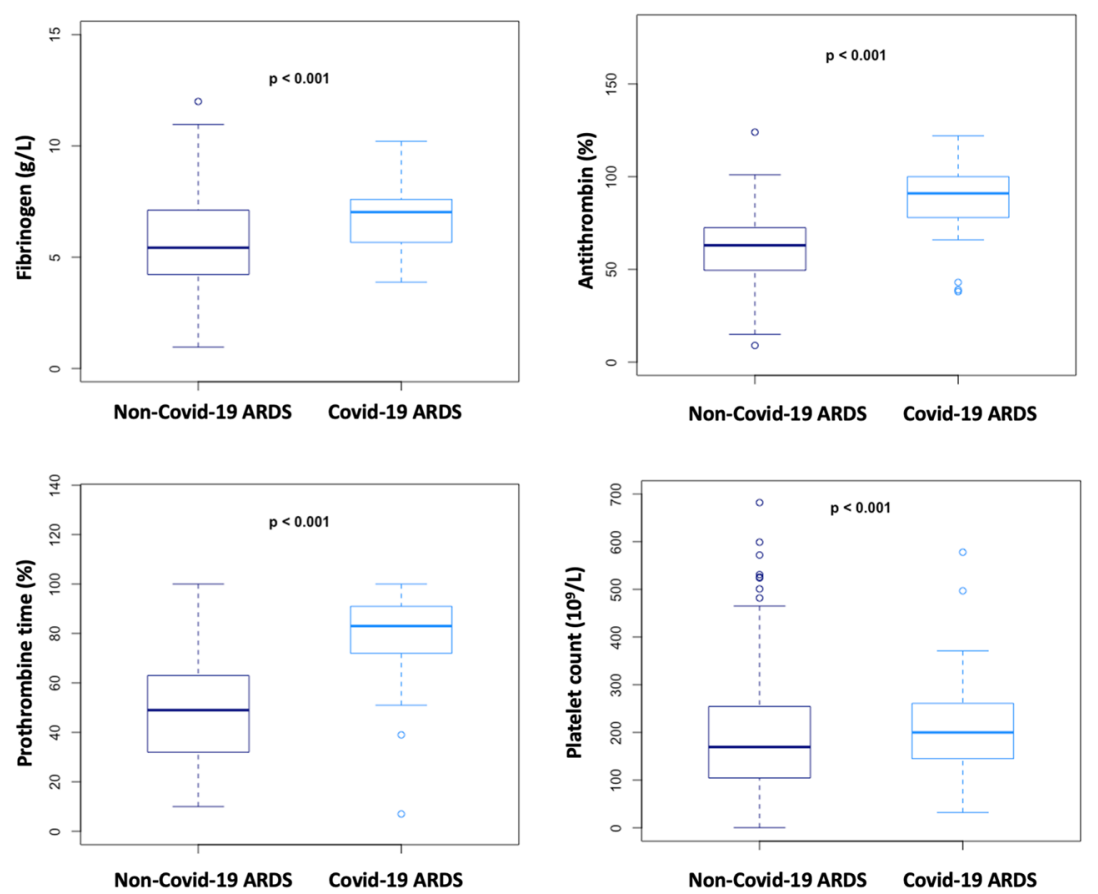

Fig. 2 Coagulation parameters of the matched COVID-19 ARDS ( $n=77$ patients); and non-COVID-19 ARDS patients ( $n=145$ patients); aPTT: activated partial thromboplastin time, PT: prothrombin time

in almost all COVID-19 patients, as demonstrated by progressive D-dimers elevation. However, the coagulation activation pattern was not the same as in our cohort of non-COVID-19 ARDS patients. It was not the same either as in septic shock without DIC: D-dimers levels were less elevated (2.27 mg/L vs. 4.30), PT, aPTT and AT were within normal ranges, and fibrinogen was higher (7.0 g/L vs. 5.6) [12]. Interestingly, while 30-40\% of septic shock patients develop DIC [13], no COVID19 patient was diagnosed with DIC using ISTH "overt" score and only 6 with JAAM-DIC score. Even the SIC score, which should detect patients at risk of developing DIC, was positive in only 22 patients.

We can therefore reasonably assume that the mechanisms leading to DIC differ in COVID-19 patients from those usually described in ICU patients. Then, the mechanisms leading to localized thrombosis (PE, stroke or mesenteric infarct) or to circuit device (either RRT or ECMO) thrombosis may not be the same either. Indeed, RRT circuit thrombosis, despite systemic anticoagulation by continuous infusion of heparin and/ or citrate [14], may be explained by both the very high level of fibrinogen and the ultrafiltration, resulting in higher concentrations inside the dialyzer capillaries, rather than by contact phase activation by the circuit itself [15]. Classical coagulation markers, prothrombin and activated thromboplastin time, and platelet count do not detect the procoagulant state [16].

Our data show that pulmonary embolism was usually diagnosed a few days after ICU admission. The incidence of pulmonary embolism was much higher in COVID-19 ARDS, as assessed through the matching with non-COVID-19 patients (11.7 vs. 2.1\%). Another prospective cohort reported only $1.3 \%$ of PE in critically ill patients [17].

The mechanisms involved in thrombosis remain unclear. Endothelial inflammation was obvious, with very high levels of vWF:Ag and FVIII. Profound hypoxemia in the pulmonary capillaries may result in vasoconstriction reducing blood flow and promoting vascular occlusion [18]. Hypoxemia also induces activation of hypoxia-inducible factors (HIFs). HIFs are heterodimeric transcriptional factors consisting of HIF $\beta$ subunit, expressed by all nucleated cells, and HIF $1 \alpha$ and HIF $2 \alpha$ subunits (for HIF1 and HIF2, respectively). Hypoxia induces HIF $2 \alpha$ subunits and decreases hydroxylation resulting in inducing or inhibition of many genes, including tissue factor (TF) and plasminogen-activator inhibitor-1 (PAI-1) [19, 20]. We did not measure PAI-1 in our patients, but we could assume that it would be very high, as it is shed by endothelial cells like vWF. 
In a healthy lung, a fine balance exists between host coagulation and fibrinolytic pathways that controls fibrin deposition and their influence on the viability of the lung epithelium. It is well known that the urokinase plasminogen activator (uPA) bound to its receptor (uPAR) increases the efficiency of fibrinolysis on epithelial cell surfaces, clearing thereby abnormal fibrin deposits from the lung [21]. Impairment of this fibrinolytic function during lung inflammation results in abnormal accumulations of fibrin in alveolar spaces due to increase in pro-coagulant activity [22]. Accordingly, data of bronchoalveolar lavage (BAL) fluid from patients with ARDS have revealed the presence of fibrin and increased levels of the uPA plasminogen activator inhibitor 1 (PAI-1) responsible for a decreased fibrinolytic activity within the alveolar space [23]. Increased PAI-1 levels were measured in the blood of SARS-CoV-infected patients during the 2002-2003 epidemic [24]. A reduced capacity to cleave and remove fibrin deposits corresponds with a poor clinical patient outcome as presence of exudates, composed of fibrin and proteinaceous material, blocks normal gas exchange [25].

Recently, Gralinsky et al. [26] using system biology and a severe acute respiratory syndrome coronavirus (SARS$\mathrm{CoV}$ ) model pathogen providing matched virologic, pathological, and transcriptomic data, concluded in a model of altered hemostatic balance defined by the expression of procoagulant and antifibrinolytic factors resulting in the induction of diffuse alveolar damage after infection. Therefore, we suggest that SARS-CoV infection overwhelms the normally protective, profibrinolytic pathway, including increased PAI-1 expression, contributing to severe ARDS.

Another factor that could contribute to thrombosis is the presence of a positive lupus anticoagulant (LA) that was detected in 50 patients out of the 57 tested (87.7\%). We can reasonably exclude false positive LA due to the presence of heparin as most patients had $<0.3 \mathrm{IU} / \mathrm{mL}$ and a heparin-neutralizing agent is contained in dRVV reagents, quenching heparin up to 0.8 anti-Xa IU/ml. LA are heterogeneous antibodies detected under various clinical circumstances where cellular damage due to infectious, autoimmune or inflammatory stimuli [27] leads to plasma membrane remodeling including the release of membrane microparticles and the exposure of phospholipids normally not accessible to the immune system. Resulting antibodies have been named anti-phospholipid antibodies (aPL). Strikingly, such LA/aPL elevations in a major proportion of COVID-19 patients have, however, rarely been observed with other pathologies, which probably reveals significant or massive cellular destruction. Of course, we cannot exclude that some patients were already positive for the LA before COVID-19 infection, since the frequency of non-symptomatic positive LA is higher in the ageing population [28].

Nevertheless, there is a strong association between high D-dimers, thrombosis and the presence of LA early in the COVID-19 course. Moreover, two patients had livedo reticularis and another one had IgM type anticardiolipin antibody at $48 \mathrm{MPL}$. In our cohort, 29 patients had acute renal failure (ARF) KDIGO3 requiring renal replacement therapy (19.3\%) and many had less severe renal failure with proteinuria (data not shown). Renal failure is often present at admission, while hypotension is not. The mechanism of ARF is probably multifactorial. It may be an association of dehydration, vascular leakage, hypoxia and aPL-associated nephropathy. Evidence of thrombotic microangiopathy in our patients is difficult to evidence as renal biopsy was not performed. Systemic inflammation-essentially via IL-6-may contribute to renal injury as observed during influenza A H1N1 [29] and ARDS [30]. ARF acts as an amplification loop [31]. Nevertheless, some patients were admitted with ARF, while dehydration was clinically evident with aqueous diarrhea for few days prior to admission. Interestingly, these patients recover diuresis with hydration without improvement in ARF arguing for an intricate mechanism. Overhydration is a major concern during ARDS, and high venous pressure (aggravated by high levels of PEEP) and venous congestion of the kidneys may also play a role in the development of ARF during ICU stay.

Some viruses are known to activate the coagulation cascade, mainly by promoting tissue factor on endothelial cells (HSV and Dengue virus) as well as on lymphoid macrophages and circulating blood cells (Ebola virus) [32]. Clinical manifestations with Dengue and Ebola viruses are disseminated intravascular coagulation with an hemorrhagic pattern [33]. Our patients with COVID19 had no such phenotype but were highly thrombotic without evidence of DIC. Moreover, this phenotype is also different from that of patients admitted to ICU with ARDS due to bacterial pneumonia and might be a specific presentation of COVID-19.

Being observational, our study has some limitations. We have notably not been able to describe the pathophysiological hypothesis leading to the high incidence of clinically relevant thrombosis in COVID-19 patients, yet we have emitted some hypothesis based on clinical and biological considerations. As a large number of COVID19 patients were still intubated at the time of data collection, the incidence of thrombotic complications is probably under-estimated. Finally, we did not have a systematic standardized assessment of thromboembolic events, and imaging was performed based on the evolution of clinical or laboratory parameters, which may have led to variations according to the treating physicians. 
This study has established that despite anticoagulation, a high number of patients with ARDS secondary to COVID-19 develop life-threatening thrombotic complications. The monitoring of anticoagulant treatment should be achieved through anti-Xa measurement, owing to changes of standard hemostasis parameters in this particular pathology. Although Tang et al. [3] suggested that anticoagulant therapy mainly with LMWH appears to be associated with better prognosis in severe COVID-19 patients meeting SIC criteria or with markedly elevated $\mathrm{D}$-dimer, higher anticoagulation targets than usual should probably be taken into consideration.

\section{Electronic supplementary materia}

The online version of this article (https://doi.org/10.1007/s00134-020-06062-x) contains supplementary material, which is available to authorized users.

\begin{abstract}
Author details
${ }^{1}$ Service de Médecine Intensive Réanimation, Nouvel Hôpital Civil, Hôpitaux universitaires de Strasbourg, 1, Place de l'Hôpital, 67091 Strasbourg Cedex, France. ${ }^{2}$ ImmunoRhumatologie Moléculaire, INSERM UMR_S1109, LabEx TRANSPLANTEX, Centre de Recherche d'Immunologie et d'Hématologie, Faculté de Médecine, Fédération Hospitalo-Universitaire (FHU) OMICARE, Fédération de Médecine Translationnelle de Strasbourg (FMTS), Université de Strasbourg (UNISTRA), Strasbourg, France. ${ }^{3}$ Service d'Anesthésie-Réanimation, Nouvel Hôpital Civil, Hôpitaux universitaires de Strasbourg, Strasbourg, France. ${ }^{4}$ Groupe Méthodes en Recherche Clinique (GMRC), Hôpital Civil, Hôpitaux universitaires de Strasbourg, Strasbourg, France. ${ }^{5}$ Radiology Department, Nouvel Hôpital Civil, Strasbourg University Hospital, Strasbourg, France. ${ }^{6}$ UMR 1260, Regenerative Nanomedicine (RNM), FMTS, INSERM (French National Institute of Health and Medical Research), Strasbourg, France. ${ }^{7}$ Service de Médecine Intensive Réanimation, Hautepierre, Hôpitaux universitaires de Strasbourg, Strasbourg, France. ${ }^{8}$ Laboratoire de Virologie Médicale, Hôpitaux universitaires de Strasbourg, Strasbourg, France. ${ }^{9}$ Laboratoire de d'Hématologie, Hautepierre, Hôpitaux universitaires de Strasbourg, Strasbourg, France. ${ }^{10}$ Innovative Therapies in Haemostasis, INSERM UMR_S 1140, Université de Paris, 75006 Paris, France.
\end{abstract}

\section{Authors' contributions}

All authors whose names appear on the submission contributed substantially to the conception and design of the study, the acquisition of data, or the analysis and interpretation of the data.

\section{Funding}

NA.

\section{Data availability}

All available data are published in the current manuscript.

\section{Compliance with ethical standards}

\section{Conflicts of interest}

The authors have no conflicts of interest to declare.

\section{Ethical approval}

The local ethics committee of the University Hospital of Strasbourg approved the study (reference CE-2020-34).

\section{Publisher's Note}

Springer Nature remains neutral with regard to jurisdictional claims in published maps and institutional affiliations.

Received: 8 April 2020 Accepted: 17 April 2020

Published online: 4 May 2020

\section{References}

1. Glass WG, Subbarao K, Murphy B, Murphy PM (2004) Mechanisms of host defense following severe acute respiratory syndrome-coronavirus (SARSCoV) pulmonary infection of mice. J Immunol 173:4030-4039

2. Emanuel EJ, Persad G, Upshur R, Thome B, Parker M, Glickman A, Zhang C, Boyle C, Smith M, Phillips JP (2020) Fair allocation of scarce medical resources in the time of Covid-19. N Engl J Med. https://doi.org/10.1056/ NEJMsb2005114

3. Tang N, Li D, Wang X, Sun Z (2020) Abnormal coagulation parameters are associated with poor prognosis in patients with novel coronavirus pneumonia. JThromb Haemost. https://doi.org/10.1111/jth.14820

4. Chen N, Zhou M, Dong X, Qu J, Gong F, Han Y, Qiu Y, Wang J, Liu Y, Wei Y, Xia J, Yu T, Zhang X, Zhang L (2020) Epidemiological and clinical characteristics of 99 cases of 2019 novel coronavirus pneumonia in Wuhan, China: a descriptive study. Lancet 395:507-513

5. Wang D, Hu B, Hu C, Zhu F, Liu X, Zhang J, Wang B, Xiang H, Cheng Z, Xiong Y, Zhao Y, Li Y, Wang X, Peng Z (2020) Clinical characteristics of 138 hospitalized patients with 2019 novel coronavirus-infected pneumonia in Wuhan, China. JAMA. https://doi.org/10.1001/jama.2020.1585

6. Rhodes A, Evans LE, Alhazzani W, Levy MM, Antonelli M, Ferrer R, Kumar A, Sevransky JE, Sprung CL, Nunnally ME, Rochwerg B, Rubenfeld GD, Angus DC, Annane D, Beale RJ, Bellinghan GJ, Bernard GR, Chiche JD, Coopersmith C, De Backer DP, French CJ, Fujishima S, Gerlach H, Hidalgo JL, Hollenberg SM, Jones AE, Karnad DR, Kleinpell RM, Koh Y, Lisboa TC, Machado FR, Marini JJ, Marshall JC, Mazuski JE, Mclntyre LA, McLean AS, Mehta S, Moreno RP, Myburgh J, Navalesi P, Nishida O, Osborn TM, Perner A, Plunkett CM, Ranieri M, Schorr CA, Seckel MA, Seymour CW, Shieh L, Shukri KA, Simpson SQ, Singer M, Thompson BT, Townsend SR, Van der Poll T, Vincent JL, Wiersinga WJ, Zimmerman JL, Dellinger RP (2017) Surviving sepsis campaign: international guidelines for management of sepsis and septic shock: 2016. Intensiv Care Med 43:304-377

7. Thachil J, Tang N, Gando S, Falanga A, Cattaneo M, Levi M, Clark C, Iba T (2020) ISTH interim guidance on recognition and management of coagulopathy in COVID-19. J Thromb Haemost. https://doi.org/10.1111/ jth. 14860

8. Tang N, Bai H, Chen X, Gong J, Li D, Sun Z (2020) Anticoagulant treatment is associated with decreased mortality in severe coronavirus disease 2019 patients with coagulopathy. J Thromb Haemost JTH. https://doi. org/10.1111/JTH.14817

9. Ranieri VM, Rubenfeld GD, Thompson BT, Ferguson ND, Caldwell E, Fan E, Camporota L, Slutsky AS (2012) Acute respiratory distress syndrome: the Berlin Definition. JAMA 307:2526-2533

10. Iba T, Di Nisio M, Thachil J, Wada H, Asakura H, Sato K, Kitamura N, Saitoh D (2016) Revision of the Japanese Association for Acute Medicine (JAAM) disseminated intravascular coagulation (DIC) diagnostic criteria using antithrombin activity. Crit Care 20:287

11. Taylor FB Jr, Toh CH, Hoots WK, Wada H, Levi M, Scientific Subcommittee on Disseminated Intravascular Coagulation of the International Society on T, Haemostasis (2001) Towards definition, clinical and laboratory criteria, and a scoring system for disseminated intravascular coagulation. Thromb Haemost 86:1327-1330

12. Delabranche $X$, Boisrame-Helms J, Asfar P, Berger A, Mootien Y, Lavigne T, Grunebaum L, Lanza F, Gachet C, Freyssinet JM, Toti F, Meziani F (2013) Microparticles are new biomarkers of septic shock-induced disseminated intravascular coagulopathy. Intensiv Care Med 39:1695-1703

13. Delabranche X, Quenot JP, Lavigne T, Mercier E, Francois B, Severac F, Grunebaum L, Mehdi M, Zobairi F, Toti F, Meziani F, Boisrame-Helms J, Clinical Research in Intensive C, Sepsis N (2016) Early detection of disseminated intravascular coagulation during septic shock: a multicenter prospective study. Crit Care Med 44:e930-e939

14. Miyakis S, Lockshin MD, Atsumi T, Branch DW, Brey RL, Cervera RH, Derksen RH, de Groot PG, Koike T, Meroni PL, Reber G, Shoenfeld Y, Tincani A Vlachoyiannopoulos PG, Krilis SA (2006) International consensus statement on an update of the classification criteria for definite antiphospholipid syndrome (APS). J Thromb Haemost JTH 4:295-306

15. Gershom ES, Sutherland MR, Lollar P, Pryzdial EL (2010) Involvement of the contact phase and intrinsic pathway in herpes simplex virus-initiated plasma coagulation. J Thromb Haemost JTH 8:1037-1043

16. Oudemans-van Straaten HM (2015) Hemostasis and thrombosis in continuous renal replacement treatment. Semin Thromb Hemost 41:91-98 
17. Lim W, Meade M, Lauzier F, Zarychanski R, Mehta S, Lamontagne F, Dodek P, McIntyre L, Hall R, Heels-Ansdell D, Fowler R, Pai M, Guyatt G, Crowther MA, Warkentin TE, Devereaux PJ, Walter SD, Muscedere J, Herridge M, Turgeon AF, Geerts W, Finfer S, Jacka M, Berwanger O, Ostermann M, Qushmaq I, Friedrich JO, Cook DJ, Investigators PRfTiCCT (2015) Failure of anticoagulant thromboprophylaxis: risk factors in medical-surgical critically ill patients. Crit Care Med 43:401-410

18. Grimmer B, Kuebler WM (2017) The endothelium in hypoxic pulmonary vasoconstriction. J Appl Physiol 123:1635-1646

19. Yan SF, Mackman N, Kisiel W, Stern DM, Pinsky DJ (1999) Hypoxia/ hypoxemia-induced activation of the procoagulant pathways and the pathogenesis of ischemia-associated thrombosis. Arterioscler Thromb Vasc Biol 19:2029-2035

20. Gupta N, Zhao YY, Evans CE (2019) The stimulation of thrombosis by hypoxia. Thromb Res 181:77-83

21. Hattori N, Sisson TH, Xu Y, Desai TJ, Simon RH (1999) Participation of urokinase-type plasminogen activator receptor in the clearance of fibrin from the lung. Am J Physiol 277:L573-L579

22. Bertozzi P, Astedt B, Zenzius L, Lynch K, LeMaire F, Zapol W, Chapman HA Jr (1990) Depressed bronchoalveolar urokinase activity in patients with adult respiratory distress syndrome. N Engl J Med 322:890-897

23. Idell S, James KK, Levin EG, Schwartz BS, Manchanda N, Maunder RJ, Martin TR, McLarty J, Fair DS (1989) Local abnormalities in coagulation and fibrinolytic pathways predispose to alveolar fibrin deposition in the adult respiratory distress syndrome. J Clin Investig 84:695-705

24. Wu YP, Wei R, Liu ZH, Chen B, Lisman T, Ren DL, Han JJ, Xia ZL, Zhang FS, Xu WB, Preissner KT, de Groot PG (2006) Analysis of thrombotic factors in severe acute respiratory syndrome (SARS) patients. Thromb Haemost 96:100-101

25. Hoste EA, Roosens CD, Bracke S, Decruyenaere JM, Benoit DD, Vandewoude KH, Colardyn FA (2005) Acute effects of upright position on gas exchange in patients with acute respiratory distress syndrome. J Intensiv Care Med 20:43-49

26. Gralinski LE, Bankhead A 3rd, Jeng S, Menachery VD, Proll S, Belisle SE, Matzke M, Webb-Robertson BJ, Luna ML, Shukla AK, Ferris MT, Bolles M, Chang J, Aicher L, Waters KM, Smith RD, Metz TO, Law GL, Katze MG, McWeeney S, Baric RS (2013) Mechanisms of severe acute respiratory syndrome coronavirus-induced acute lung injury. mBio 4:e00271

27. Giannakopoulos B, Krilis SA (2013) The pathogenesis of the antiphospholipid syndrome. N Engl J Med 368:1033-1044

28. Goldman-Mazur S, Wypasek E, Karpinski M, Stanisz A, Undas A (2019) High detection rates of antithrombin deficiency and antiphospholipid syndrome in outpatients aged over 50 years using the standardized protocol for thrombophilia screening. Thromb Res 176:67-73

29. Bautista E, Arcos M, Jimenez-Alvarez L, Garcia-Sancho MC, Vazquez ME, Pena E, Higuera A, Ramirez G, Fernandez-Plata R, Cruz-Lagunas A, GarciaMoreno SA, Urrea F, Ramirez R, Correa-Rotter R, Perez-Padilla JR, Zuniga J (2013) Angiogenic and inflammatory markers in acute respiratory distress syndrome and renal injury associated to A/H1N1 virus infection. Exp Mol Pathol 94:486-492

30. Seeley EJ (2013) Updates in the management of acute lung injury: a focus on the overlap between AKI and ARDS. Adv Chronic Kidney Dis 20:14-20

31. Malek M, Hassanshahi J, Fartootzadeh R, Azizi F, Shahidani S (2018) Nephrogenic acute respiratory distress syndrome: a narrative review on pathophysiology and treatment. Chin J Traumatol 21:4-10

32. Antoniak S, Mackman N (2014) Multiple roles of the coagulation protease cascade during virus infection. Blood 123:2605-2613

33. Basler CF (2017) Molecular pathogenesis of viral hemorrhagic fever. Semin Immunopathol 39:551-56 